\title{
RESEARCH ON BLENDED TEACHING REFORM BASED ON SPOC -TAKING THE COURSE "FOUNDATION OF ENTREPRENEURSHIP" AS THE EXPERIMENTAL SUBJECT
}

\author{
Wang Yong ${ }^{1}$ and Zeng Qinghui ${ }^{2 \star}$ \\ 1Dr, Jinan University, China, 1057394877@qq.com \\ ²Dr, Jinan University, China, 93430749@qq.com \\ ${ }^{*}$ Corresponding Author
}

\begin{abstract}
With the general course "Foundation of Entrepreneurship" opened by the Entrepreneurship College of Jinan University for all students as the object, the national excellent online open course "entrepreneurship foundation" as the theoretical teaching platform, the "entrepreneurship training camp" as the practical teaching platform, and combining with the SYB entrepreneurship education practice mode, the SPOC-based "online + offline" hybrid teaching experiment teaching experiment was carried out. The experimental results show that: the blended teaching method of SPOC is conducive to the interaction between teachers and students, better classroom atmosphere, higher students' participation, and can produce greater classroom effect and curriculum benefits for such a practical course like "Foundation of Entrepreneurship".
\end{abstract}

Keywords: Small Private Online Course (SPOC); Blended teaching; Foundation of Entrepreneurship

Funding projects: This paper is the phased research results of the collaborative education project " Research on the Basic Teaching Reform of Entrepreneurship Combining Principles and Training " of the Ministry of Education (No. 201901226027) and the 2018 high-quality engineering construction project of Guangdong undergraduate universities, "Practice Education, Innovation and Entrepreneurship Teaching Team" (article number: Yuejiao Gaohan [2018] No. 179).

\section{INTRODUCTION}

Under the background of "Internet plus education", using the online teaching platform to carry out blended teaching is the only way leading to education reform. The hybrid teaching mode combines the advantages of both online teaching and traditional offline teaching. By teaching simultaneously online and offline, it widens students' learning channels, expands teaching coverage, improves teaching quality, and cultivates students' ability in an all-round way.

SPOC (small private online courses) defined as a small-scale restricted online course, integrates micro class and small-scale professional education to form a unique education mode of SPOC. Different from the traditional teaching mode, SPOC makes full use of the rapid development of Internet information technology to spread high-quality teaching resources through online learning. In this teaching mode, students can use their pockets of time to learn, at the same time, they don't have to enter a real classroom for knowledge, which greatly improves the flexibility of education and the learning efficiency of students. 
In China, "Foundation of Entrepreneurship" is the core course of entrepreneurship education for all college students, generally no less than 32 classes and accounting for no less than 2 credits. Its teaching goal is to spread entrepreneurial knowledge, improve students' entrepreneurial ability and cultivate their entrepreneurial spirit. "Entrepreneurship Foundation" is a very theoretical, policy-supported, scientific and practical course. The teaching process should follow the laws of education, adhere to the combination of theoretical teaching and case analysis, group discussion and role playing, experience imparting and entrepreneurial practice. Through integrating knowledge, discussion and practice, the course can attract students' interest, and inspire their creativity with high level and quality of teaching.

It is obvious that the blended teaching mode coincides with the curriculum features of "Entrepreneurship Foundation", which is the main reason why we choose this course as the experimental subject of teaching reform.

\section{THE BLENDED TEACHING GOAL OF THIS COURSE BASED ON SPOC}

Through the SPOC-based teaching mode of combining open video courses with face-to-face entrepreneurship training, we can carry out creativity, innovation and entrepreneurship education programs for students of Jinan University, to inspire their enthusiasm for commercial use of knowledge, raise their awareness of the significance of entrepreneurial achievement and expand their vision of operational resources. The final goal of this course is to stimulate students to carry out innovative and entrepreneurial activities.

This project takes the "Foundation of Entrepreneurship", opened by the Entrepreneurship College of Jinan University for all students as the reform object. The video course resources, "Entrepreneurship Foundation", recorded by Professor Zhang Yaohui in 2016, was launched on the MOOC platform in 2017, and was rated as a national premium online open course the next year. We also take advantage of the "entrepreneurship training camp" -- the entrepreneurship practice education platform in Jinan University. To perform this experiment, we integrate online video courses with offline entrepreneurship training, using both ways of online video lectures plus Q\&A and offline classroom discussions plus training.

\section{TEACHING MODE DESIGN AND REFORM MEASURES}

According to the schedule of the project, the teaching team made theoretical preparations and specific research plans. The project setting requires the Entrepreneurship College of Jinan University as the main organizer, and Jinan University's three innovation education (creative, innovation, entrepreneurship) as the theoretical basis. We use the state-level online course, "Entrepreneurship Foundation" as our platform online and the "entrepreneurship training camp" of Jinan University as the teaching channel offline. According to the basic strategy of "design-practice- modification-practice-improvement", we carried out the research by copying the SYB entrepreneurship education practice mode to head for the reform direction of new forms, new contents and new methods.

In the preparatory stage, the members of the research group systematically studied the existing theories and models. The first part was to sort out the three-creation education theory of Jinan University then have experts demonstrate it and initially formed the idea of performing related research, with the original "Entrepreneurship training Camp" of the Entrepreneurship College of Jinan University as the blueprint, and Professor Zhang's team's "Entrepreneurship Foundation" MOOC course as the theory foundation, by intimating the SYB entrepreneurship education practice mode. The second part was to conduct research in colleges and universities in Guangzhou to learn their experience in innovation and entrepreneurship education. While basically followed the original research plan, we also fine-tuned the relevant research according to the actual situation, and carried out two rounds of practical education experiments from January to May 2019 and July to September 2019.

\section{TEACHING MODE DESIGN AND REFORM MEASURES}

The SPOC teaching mode of this project consists of two parts, namely the online theoretical teaching part and the offline practical one.

\subsection{The Online Theoretical Teaching Part}

According to the three-innovation education theory of Jinan University, we shifted the "Entrepreneurship Foundation: principles and training", a general course of entrepreneurship education offered by the Entrepreneurship college of Jinan University into the "Online + offline" mode. For the online part, we take the "Entrepreneurship Foundation", rated as the national high-quality online open course in 2018 , as the video 
course resources and the Entrepreneurship Foundation edited by Zhang Yaohui and Wang Yong (Chongqing University Press) as the supporting textbook.

The course is lectured by Professor Zhang Yaohui of the School of Management of Jinan University, the famous teacher of the National Ten Thousand talents Plan, and the Guangdong Special Branch Program. The teaching content focuses on the moral education and means to inspire students to cultivate their independent learning ability through the participation of students. The MOOC course uses video teaching in a dialogue mode. Each lesson introduces the basic principles with entrepreneurial stories, demonstrates the principles with four to six questions, and finally discusses the application of the principles. There are nine units in the course, with four units as its core: one is the quality of entrepreneurs, discussing the methods and ways to become a firm entrepreneur; the second is identifying entrepreneurial opportunities, discussing the methods of identifying entrepreneurial opportunities; the third is business model design, from the integration of entrepreneurial opportunities and entrepreneurial resources to form their own business logic; the fourth is entrepreneurial team and plan, talking about building teams with action capabilities as the goal, and writing and presenting entrepreneurial plans based on team action ability. The curriculum complies with the idea of student-orientation, positioning educators as transforming people/reformers.

The online course consists of 11 chapters and a video duration of more than 600 minutes, with teaching materials, courseware, rich text, tests and examinations. Students can study by themselves after joining the course, and they can also communicate with classmates and teachers in the discussion area.

\subsection{The Offline Practical Teaching Part}

The offline practical teaching is divided into two parts: classtime training and practical teaching.

The classroom training mainly learns from the training mode of SYB and SIYB China project training content (including game module) and Parkson practice teaching method (game teaching method). The main feature of it is the use of experiential teaching method, which is versatile, flexible and modular, so it helps improve the teaching effect of entrepreneurship educators and students' interest in participation. The main reference materials are the SYB series of training materials: How to Start a Business to Improve your Business (including the game section) and Teaching Entrepreneurship-A Practice-Based Approach co-authored by three professors: Heidi M.neck, Patricia G.Greene and Candida G.Brush (Machinery Industry Press, 2015).

The other session includes business study tours, 24-hour "survival" challenges, and business plan writing and presentation (also known as perfect speech). The business study tour is mainly to visit and analyze wellknown enterprises and incubators in Guangdong. The purpose of it is to help students learn to observe and discover business opportunities, and know about the history and business models of well-known enterprises. The 24-hour survival challenge is a team work, giving teams a certain amount of start-up capital (usually 500 mur1000 yuan). And within 24hours, students can take any business action on a legal basis to obtain profits. The purpose is to experience entrepreneurial process, make good business plans, effective team communication, and capital management. Entrepreneurship plan writing and presentation require students in the form of a team or group to complete a high-quality business plan and fully display it. The purpose is to test the teaching results of the training camp and improve the students' project roadshow ability.

\section{THE EFFECT OF TEACHING PRACTICE APPLICATION}

After preliminary project research, we formed a complete blended teaching plan based on SPOC for the course "entrepreneurial foundation", and conducted two rounds of curriculum teaching experiments.

The two rounds of experiments basically achieved the expectation of the curriculum reform design. We have fulfilled the SPOC teaching plan including the online theoretical learning and offline practical teaching (curriculum design, teaching plan, courseware) two parts and held two rounds of practical teaching activities. During the course, more than 150 students signed up and 67 participated in training, resulting in more than 30 entrepreneurial Ideas.

After two SPOC teaching experiments, we find that the teaching practice application is effective. First, students are interested in teaching modes and have a good classroom atmosphere. For the online part, students can freely arrange their study time, free from the restrictions of the location, and can watch videos repeatedly, reread textbooks, and communicate with each other in the comment area, so as to study the theoretical content in depth. Classroom training adopts experiential teaching, making students the main body of the classroom, through group collaboration, classroom discussion, role-playing, games, etc., to make study entertaining and attract students. During the business study tour, students are enthusiastic in visiting enterprises and observing the business model on the spot. Another is that the number of students joining us 
this time has greatly increased after the first course test and under the recommendation and influence of the first course of students. Also, during the development of the project, a large number of entrepreneurial projects IDEAs were generated, which greatly stimulated students' enthusiasm for entrepreneurship.

\section{OUR INNOVATION}

First, the form of the classroom is novel and attractive. In the traditional class teaching, the time is limited and the content is single. This course adopts online video teaching which students can watch in their own schedule. It also provides offline entrepreneurship training and practice, so the students receive face-to-face guidance from entrepreneurship tutors in class. We integrate the SYB entrepreneurship education practice mode with the content of entrepreneurship education in Jinan University. Through the trinity model of "theory, training and practice", the teaching contents are both theoretical in depth and easy- to-understand for students.

Second, the whole offline teaching part adopts the mode of participatory training. The training process takes the trainees as its core, making full use of both traditional and modern teaching methods, like games, case studies, group discussions, brainstorming, positive and negative debates, role-playing, entrepreneurial simulation, classroom speeches and other various participatory teaching methods to improve students' initiative.

The third point is that we emphasize the importance of action in the process of starting a business through three practical activities: business study tour, 24-hour survival challenge and perfect speech. Through this part, the trainees can experience every stage of the entrepreneurial process and exercise their practical skills to organize a team and allocate group task.

\section{CONCLUSION}

This project has formed a perfect "online + offline" teaching mode, with clear goals, reasonable plan, various methods and remarkable achievements. Combined with the "Entrepreneurship training Camp" of Entrepreneurship College, this project has become a regular three-innovation education project and has won the favor of students. After the two rounds of teaching experiments, many students inquire about the opening time of the next course. With the strong support of the Entrepreneurship College, we plan to carry out this project twice a year in Jinan University, and due to the use of entrepreneurship education seminars and other platforms, we have achieved the agreement with a number of universities to carry out SPOC entrepreneurship education together. In the future, we will classify students participating in SPOC into more detailed types (like arts, science, economics, management, news, medicine, etc.), continue to increase the number of SPOC courses and invite more professors to give lectures, in order to do a good job in entrepreneurship practice education.

\section{REFERENCE LIST}

Bruce R.Barringe (2016). Preparing Effective Business Plans-An Entrepreneurial Approach[M]. Translated by Chen Zhongwei,etc. China Machine Press.

Heidi M.neck, Patricia G.Greene, Candida G.Brush (2015). Teaching Entrepreneurship-A Practice-Based Approach[M]. Translated by Xue Hongzhi, etc. China Machine Press.

Center Organized (2008). Start Your Business[M]. China Labor and Social Security Press.

Zhang yaohui, Zhang Shuyi, Song Yuxiang, Wang Yong (2018). Foundation of Entrepreneurship. Chongqing University Press. 